\title{
Enduring effects of a 5-week behavioral activation program for subthreshold depression among late adolescents: an exploratory randomized controlled trial
}

This article was published in the following Dove Press journal:

Neuropsychiatric Disease and Treatment

Koki Takagaki,' Yasumasa

Okamoto, ${ }^{2}$ Ran Jinnin, ${ }^{2}$ Asako

Mori, ${ }^{2}$ Yoshiko Nishiyama, ${ }^{3}$

Takanao Yamamura, ${ }^{4}$ Satoshi

Yokoyama, ${ }^{2}$ Syouichi Shiota, ${ }^{5,6}$

Yuri Okamoto,' Yoshie

Miyake, ' Akiko Ogata, ${ }^{7}$

Yoshihiko Kunisato, ${ }^{8}$ Haruki

Shimoda, ${ }^{9}$ Norito Kawakami, ${ }^{10}$

Toshi A Furukawa," ' Shigeto

Yamawaki $^{2}$

'Health Service Center, Hiroshima, Japan; ${ }^{2}$ Department of Psychiatry and Neurosciences, Hiroshima University, Hiroshima, Japan; ${ }^{3}$ Haruma City Office, Haruma, Japan; ${ }^{4}$ Kanazawa University Hospital Neuropsychiatry, Kanazawa, Japan; ${ }^{5}$ Japan Society for the Promotion of Science, Tokyo, Japan; ${ }^{6}$ Department of Cognitive Psychology in Education, Graduate School of Education, Kyoto University, Kyoto, Japan; ${ }^{7}$ Department of Psychology, Hiroshima University, Hiroshima, Japan; ${ }^{8}$ Department of Psychology, School of Human Sciences, Senshu University, Kawasaki, Japan;

${ }^{9}$ Department of Hygiene and Preventive Medicine, School of Medicine, Iwate Medical University, Morioka, Japan; ${ }^{10}$ Department of Psychiatry of Mental Health, The University of Tokyo, Tokyo, Japan; "Department of Health Promotion and Human Behavior and of Clinical Epidemiology, Kyoto University Graduate School of Medicine/School of Public health, Kyoto, Japan

Correspondence: Yasumasa Okamoto Department of Psychiatry and Neurosciences, Hiroshima University, I-2-3 Kasumi, Minami-ku, Hiroshima 734-855I, Japan

Tel +81822575208

Fax +81822575209

Email oy@hiroshima-u.ac.jp
Background: No significant effect of psychological treatment has been reported from meta-analysis of subthreshold depression patients and control subjects at 1-year follow-up. However, behavioral activation is a simpler and more cost-effective treatment than cognitive behavioral therapy. The primary purpose of this study was to assess by comparison to an assessment-only control group whether the effects of behavioral activation program for depressive symptoms can persist up to 1-year follow-up without the use of antidepressants or other psychotherapy.

Patients and methods: Late adolescent students were the population targeted in this study. Participants were allocated randomly to an intervention group $(n=62)$ or a control group $(n=56)$. Treatment consisted of five-weekly 60-minute sessions. Participants underwent a structured interview and completed self-report scales at 1 year post-assessment.

Results: Late adolescent students receiving treatment had significantly lower mean Beck Depression Inventory, second edition scores at 1-year follow-up than control group students. The effect size (Hedges' $g$ ) for between-group differences at 1-year follow-up was -0.41 .

Conclusion: Our behavioral activation program is simple and short. Nevertheless, the results obtained at 1-year follow-up of the control group and late adolescent students receiving treatment indicated a significant difference in their Beck Depression Inventory, second edition scores. Our 5-week behavioral activation program based on behavioral characteristics for subthreshold depression might be promising for subthreshold depression. The sample examined for this study imposed some study limitations.

Keywords: behavioral activation, first-year university students, randomized controlled trial, subthreshold depression

\section{Introduction}

Subthreshold depression is defined as the exhibition of clinically significant depressive symptoms that do not meet the diagnostic criteria for major depressive disorder (MDD). ${ }^{1}$ Subthreshold depression is a major risk factor for subsequent development of more severe depressive symptoms. ${ }^{2-5}$ The probability of MDD is known to increase steadily during adolescence, that is, $12-20$ years. ${ }^{6}$ Although not meeting the full criteria, subthreshold depression has been associated with severe problems such as negative impact on academic performance and social activities, ${ }^{7}$ which might be as severe as those associated with full depression. ${ }^{8}$ 
An earlier report described that the use of antidepressant medication by adolescent patients is associated with a modestly increased risk of suicidality. ${ }^{9}$ It is, therefore, especially important to assess the effectiveness of psychological treatment programs only, without antidepressants, for late adolescents with subthreshold depression. Several earlier reports of studies with longer follow-up (1 year) have described that cognitive behavioral therapy (CBT) can reduce the risk of MDD. ${ }^{10-12}$ Nevertheless, a meta-analysis of psychological treatments for subthreshold depression found no significant effect of psychotherapy for depressive symptoms at 1-year follow-up ${ }^{13}$ and found no significant effect of CBT on the incidence of MDD at follow-up. ${ }^{13}$

For adolescent and late adolescent patients with depression, earlier reports have described behavioral activation as an effective treatment. ${ }^{14,15}$ For university students with moderately depressive symptoms, behavioral activation was found to have significantly greater reduction in depressive symptoms from pretreatment to posttreatment. ${ }^{16}$ Although the meta analysis of behavioral activation for children and adolescents reported that behavioral activation was effective from pretreatment to posttreatment, the long-term effect has not yet been elucidated for children and adolescent patients. ${ }^{17}$ An earlier systematic review of behavioral activation programs for depression revealed an effect size of -0.35 (Hedges' $g$ ) in comparison with control conditions at 6-9 months of follow-up. ${ }^{18}$ The effectiveness of behavioral activation in follow-up might not have a sufficient effect. No report of the relevant literature describes a study that examined the long-term efficacy of brief behavioral activation for subthreshold depression. Recently, we conducted a randomized controlled trial (RCT) to examine the efficacy of a brief five-session behavioral activation program for late adolescent patients with subthreshold depression. ${ }^{19}$ Results demonstrated that late adolescent students receiving this treatment exhibited significantly greater improvement in self-reported depressive symptoms than the assessment-only control group. The effect size was Hedges' $g$ of $-0.90 .{ }^{19}$ It has not been reported whether the effects of this behavioral activation program can be maintained over the long term.

Therefore, the primary purpose of this study was to assess whether a behavioral activation program without antidepressants for depressive symptom can be maintained for depressive symptoms up to 1 year and be compared with the assessment-only control group. The secondary aim was to explore whether the behavioral activation program can decrease the risk of developing MDD or not.

\section{Patients and methods Research design}

Details of the study design of this RCT were presented in an earlier report (UMIN000011967). ${ }^{19}$ The 1-year follow-up study was already planned in the original RCT. Furthermore, the same student sample as that examined in an earlier study ${ }^{19}$ was followed up 1 year later in the present study.

\section{Procedures}

Details of procedures of this RCT were presented in an earlier report. ${ }^{19}$ Participants were recruited from Hiroshima University over a 2-year period during 2013-2014 (Figure 1). The Beck Depression Inventory, second edition (BDI-II) is administered annually to all first-year students of the university as a part of their health examination, which is conducted at the Health Service Center of Hiroshima University. We randomly selected the first-year students with a BDI-II score $\geq 10$ using the Microsoft Excel randomization function. Recruitment took place through email at a public information sharing center. Then, we held a meeting to explain the study contents. After all the participants had signed a written informed consent form, participants received the Composite International Diagnostic Interview (CIDI) and completed self-report scales via the Internet. An expert of the Department of Clinical Research, who was independent of the research team that conducted this study, developed a sequential assignment list using computer-generated random numbers to allocate the participants to a treatment or a control group randomly at a 1:1 ratio. The random sequence was stratified by sex and depression severity during screening (BDI-II score $\leq 13$, BDI-II score $\geq 14$ ). The group allocation was masked in the entry and in the CIDI assessment. A psychiatrist interviewed the participants and assessed the risk of a future acute suicide attempt if a participant had a history of attempted suicide based on CIDI criteria. Furthermore, participants who met the criteria for a possible acute suicide attempt received counseling from a psychiatrist. Participants joined the RCT. ${ }^{19}$ We contacted the participants by email and telephone 1 year later. Participants received telephone interviews by CIDI and completed self-report scales via the Internet 1 year after the assessment by blind testers who did not know the allocation. In CIDI assessment of 1-year follow-up, allocation to the treatment group or control group was masked.

\section{Participants}

We recruited late adolescent students with subthreshold depression during a 2-year period of 2013-2014 at Hiroshima 


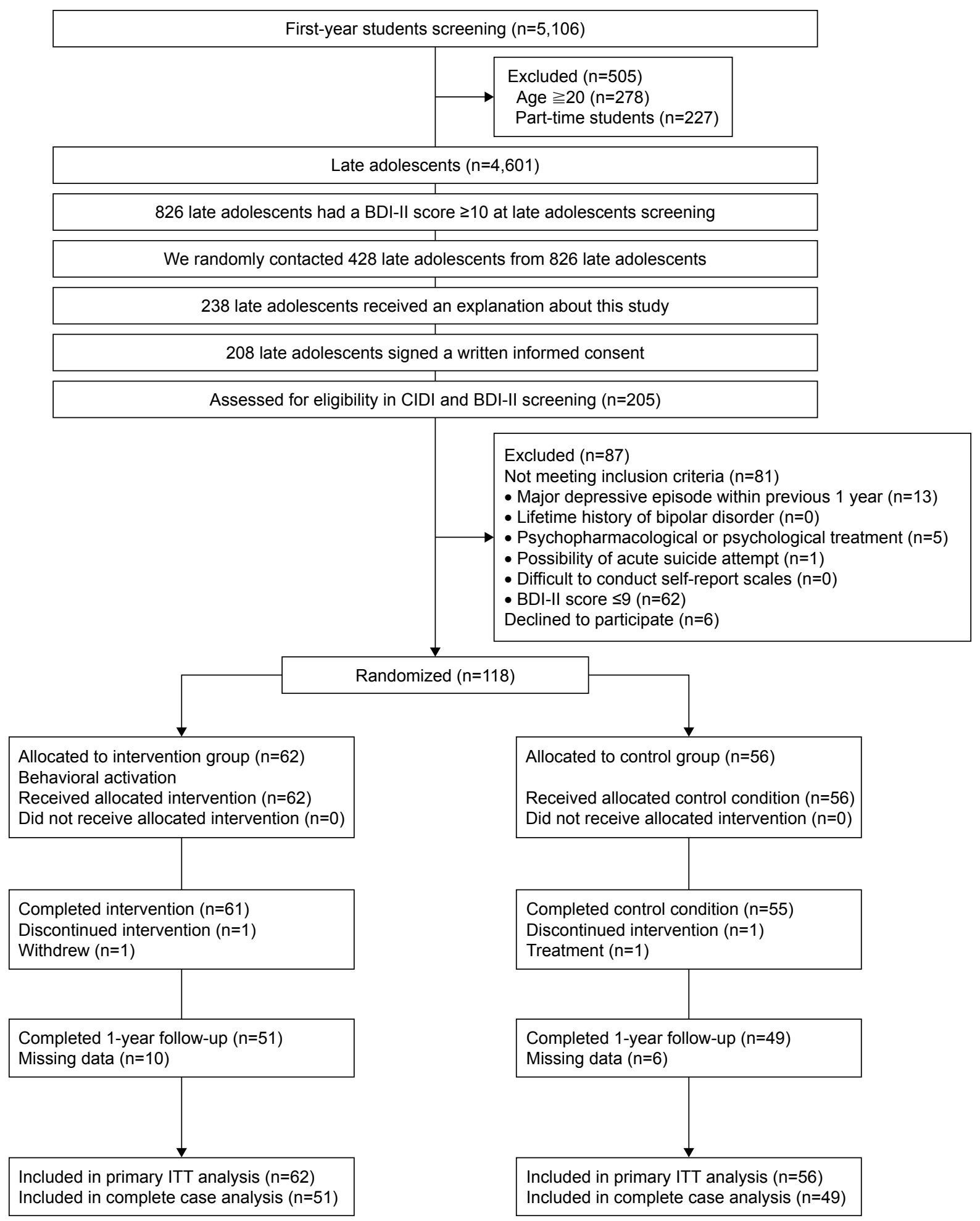

Figure I Study flow chart.

Abbreviations: BDI-II, Beck Depression Inventory, second edition; CIDI, Composite International Diagnostic Interview; ITT, intention-to-treat.

University in Japan. For this study, the inclusion criteria were the following: 18-19-year-old first-year university student at Hiroshima University, BDI-II score $\geq 10$ according to earlier studies, ${ }^{20,21}$ participants who did not have a major depressive episode during the previous year as determined by the structured clinical interview with the CIDI, and not undergoing psychopharmacological or psychological treatment. The exclusion criteria were the following: a lifetime history of 
bipolar disorder according to earlier studies, ${ }^{20-24}$ possibility of an acute suicidal attempt, difficulty understanding the study purpose, or having a severe physical disease and "difficulty in completing self-report scales".

\section{Intervention}

Our behavioral activation program consisted of five-weekly 60-minute sessions. The program emphasized increased access to positive reinforcement activities to improve the rate of response-contingent positive reinforcement. Our behavioral activation program was modeled after the behavioral activation component of a CBT program developed based on earlier studies of adult depression in the USA ${ }^{25,26}$ and which has been demonstrated in an RCT to be effective for subthreshold depression in the workplace in Japan. ${ }^{21}$ Details of intervention of this RCT can be found in an earlier report. ${ }^{19}$

\section{Control group}

The control group participants were examined for outcome measures. They received baseline, posttreatment, and follow-up assessments at approximately the same time as the intervention group did. The control group participants in this study received no medical treatment, usual care, or any educational information.

\section{Measures}

\section{Primary outcome}

The Japanese version of the BDI-II

BDI-II consists of 21 self-report items scored on a four-point scale. It is used to measure depressive symptoms. ${ }^{27}$ Good reliability and validity have been reported for the Japanese version of BDI-II. ${ }^{28}$ BDI-II was administered at baseline, at the end of treatment, and at 1-year follow-up. The primary outcome of this report is BDI-II scores at 1-year follow-up. The internal consistencies of the BDI-II in pretreatment, posttreatment, and 1-year follow-up were assessed using Cronbach's $\alpha$. The internal consistencies for all time BDI-II were also acceptable: pretreatment $\alpha=0.79$, posttreatment $\alpha=0.74$, and 1 -year follow-up $\alpha=0.87$.

\section{Secondary outcome}

\section{Composite International Diagnostic Interview}

The CIDI is a structured interview for assessing mental disorders. ${ }^{29}$ Good reliability and validity have been reported for the Japanese ver 3.0 of the CIDI. ${ }^{30}$ We used the Japanese 3.0 version of the CIDI in screening and 1-year follow-up. We assessed for 12-month history of MDD, generalized anxiety disorder, panic disorder, social phobia, and posttraumatic stress disorder. In addition, each participant was assessed for the lifetime history of bipolar disorder. Because earlier reports have described the comorbidity rate for depression and anxiety as high, ${ }^{31}$ we included generalized anxiety disorder, panic disorder, social phobia, and post-traumatic stress disorder in screening for this study.

We administered CIDI to the participants before baseline and at 1-year follow-up. At the follow-up assessment, we limited the time frame to the previous year to ascertain the new incidence of MDD. The secondary outcome of this report is the incidence of MDD during 1 year of follow-up.

\section{Sample size calculation}

Sample size calculations were conducted at the study design stage. ${ }^{19}$

An earlier report described a mean effect size of $d=0.87$ in behavioral activation group vs a control group at posttest. ${ }^{32}$ The mean effect size found for psychotherapies for subthreshold depression was $d=0.42 .{ }^{13}$ Because effect sizes suggest that $d=0.5$ indicates a medium effect, ${ }^{33}$ we set the effect size in our study as a medium effect $(d=0.50)$. We estimated a minimum of 64 participants in each group at the study design stage (power $=0.80$ and $\alpha=0.05, d=0.50$ for an unpaired $t$-test). Therefore, the power might be insufficient to detect differences in incidence of MDD that occurs over 1 year.

\section{Statistical analysis}

All statistical analyses were conducted using software (SPSS Statistics 22; IBM Corp.).

\section{Primary outcome analysis}

The primary purpose of this study was exploratory examination of whether behavioral activation program effects persisted at 1-year follow-up. The primary point was estimation of the intervention effect on depressive symptoms between the original assigned groups at 1-year follow-up. Analysis of variance with repeated measures is limited to cases with complete data or with imputation of missing data. Some statistical approaches are useful for dealing with missing data that do not necessarily require formal imputation methods. ${ }^{34}$ For example, the linear mixed model for repeated measure approach was used for analyzing outcomes measured repeatedly over time. ${ }^{34-36}$ To examine the effects of treatment on primary outcomes at 1-year follow-up, the primary analysis was conducted using a linear mixed model for repeated measures. The random effects of this model were intercepts. 
Therefore, because individual differences are explained as a variable effect, the mode of analysis of this research is a model showing change from the individual baseline. The model predictors were categorical time (pretreatment, posttreatment, 1-year follow-up), treatment condition, and time $\times$ treatment interaction as fixed effects. We applied intentionto-treat (ITT) analysis between the original assigned groups. We conducted post hoc analysis if an interaction was found. Effect sizes were calculated and reported as Hedges' $g^{37}$ for between-group differences in 1-year follow-up, using the observed standard error (SE) at follow-up.

Some participants might not complete the full protocol of a longitudinal study. Sensitivity analyses can be conducted using different approaches to ascertain how robust the primary analysis is for the chosen method for handling missing data. ${ }^{34}$ For sensitivity analysis, we conducted a complete case analysis to assess the discrepancy between ITT and complete case analysis.

\section{Secondary exploratory outcome analysis}

Next, we applied Cox proportional hazard analysis for exploratory assessment of the differences in time for the development of MDD between the intervention group and the control group to adjust for lifetime diagnosis of MDD. In CIDI, participants who met the criteria for MDD reported the time that participants developed depressive symptoms.

\section{Ethics approval}

Approval for the study was obtained from the ethics committee of Hiroshima University. All participants signed a written informed consent form.

\section{Results \\ Participant enrollment}

Figure 1 presents the study flow. Of the 208 students who gave their informed consent to participate, 205 (98.6\%) completed screening. The mean score of BDI-II during screening was 13.53 . Then, the 108 participants who satisfied all the eligibility criteria were allocated randomly to the intervention or control group (Table 1). The BDI-II average score of the sample consisting of 118 students was 13.02 . One intervention group participant dropped out. One control group participant underwent psychopharmacological or psychological treatment during 5 weeks. At 1-year follow-up, seven intervention group participants did not complete the CIDI and self-report scales. Three intervention group participants had undergone psychopharmacological or psychological treatment during the follow-up period. Five control
Table I Descriptive data of groups

\begin{tabular}{|c|c|c|c|}
\hline \multirow[t]{2}{*}{ Characteristics } & $\begin{array}{l}\text { Intervention } \\
\text { group }\end{array}$ & \multirow{2}{*}{$\begin{array}{l}\text { Control } \\
\text { group } \\
n=56\end{array}$} & \multirow[t]{2}{*}{$P$-value } \\
\hline & $n=62$ & & \\
\hline Female/male & $24 / 38$ & $21 / 35$ & 1.00 \\
\hline Mean age (years) & I8.23 (0.42) & $18.20(0.40)$ & 0.70 \\
\hline Live alone/live with family & $48 / 14$ & $43 / 13$ & 1.00 \\
\hline Enter the university of first choice & $33 / 29$ & $33 / 23$ & 0.66 \\
\hline $\begin{array}{l}\text { Lifetime diagnosis of major } \\
\text { depressive disorder (yes/no) }\end{array}$ & $5 / 57$ & $8 / 48$ & 0.43 \\
\hline \multicolumn{4}{|l|}{ Comorbidity } \\
\hline $\begin{array}{l}\text { Diagnosis of any anxiety disorder } \\
\text { in the previous year (yes/no) }\end{array}$ & $7 / 55$ & $14 / 42$ & 0.09 \\
\hline BDI-II (pretreatment) & $12.76(6.66)$ & $13.30(5.95)$ & 0.64 \\
\hline
\end{tabular}

group participants did not complete the CIDI and self-report scales. One control group participant had undergone psychopharmacological or psychological treatment during the follow-up. Therefore, missing data of the intervention group were those of ten participants from posttreatment to 1-year follow-up. Missing data of the control group were those of six participants from posttreatment to 1-year follow-up. No significant difference was found in the rates of missing data $\left(\chi^{2}(1)=0.73, P=0.43\right)$.

\section{Depressive symptoms (primary outcome)} Results obtained from a linear mixed model

The primary point was estimation of the intervention effect on depressive symptoms between the original assigned groups at 1-year follow-up. To assess the effects of treatment on primary outcomes at 1-year follow-up, primary analysis was conducted using a linear mixed model for a repeated measures approach in the original assigned groups (62 participants in the intervention group and 56 participants in the control group). Significant interaction was found between groups and times $(F$ value $=9.01$, degrees of freedom $=216.45, P<0.01$; Figure 2). Significant difference was found between the mean estimates for the intervention group and the control group at 1-year follow-up (intervention group, mean estimate $=11.00$, $\mathrm{SE}=0.89$, 95\% CI: 9.24 to 12.76 ; control group, mean estimate $=13.83, \mathrm{SE}=0.91,95 \% \mathrm{CI}: 12.00$ to 15.61 ; estimated mean difference $=2.83,95 \% \mathrm{CI}: 0.28$ to $5.33, P=0.03$ ), as shown in Table 2. The effect size (Hedges' $g$ ) for betweengroup differences at 1-year follow-up was -0.41 (95\% CI: -0.77 to -0.04$)$. Additionally, a significant difference was found in the mean estimates between the intervention group and control group at posttreatment (intervention group, mean estimate $=7.03, \mathrm{SE}=0.84,95 \% \mathrm{CI}$ : 5.38 to 8.68 ; control group, 


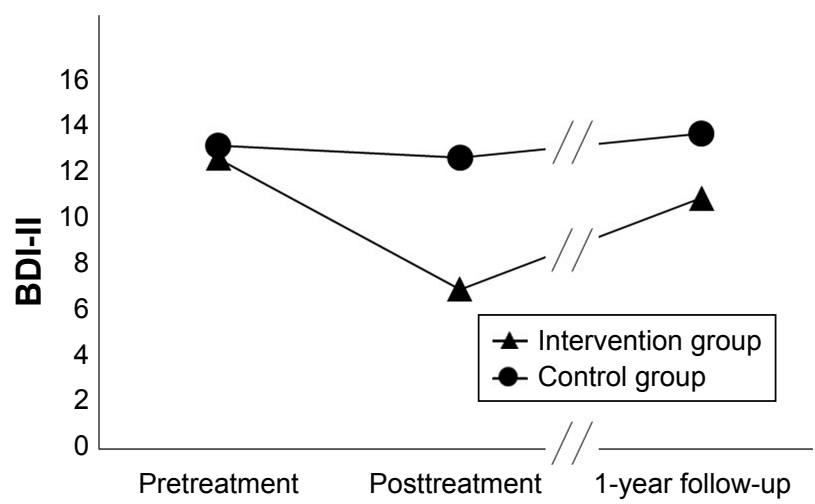

Figure 2 Changes in BDI-II score from pretreatment to I-year follow-up. Abbreviation: BDI-II, Beck Depression Inventory, Second edition.

mean estimate $=12.77, \mathrm{SE}=0.88,95 \% \mathrm{CI}: 11.03$ to 14.51 ; estimate mean difference $=5.74,95 \% \mathrm{CI}: 3.34$ to $8.14, P<0.01$ ). The effect size (Hedges' $g$ ) for between-group differences in 1-year follow-up was -0.87 (95\% CI: -1.24 to -0.49$)$.

Next, because this study had missing data, we conducted complete case analysis (intervention group, $\mathrm{n}=51$; control group, $n=49$ ) and then conducted sensitivity analysis and examined the discrepancy between ITT and complete case analysis. Significant interaction was found between groups and times $(F$ value $=9.42$, degrees of freedom $=196, P<0.01$; Figure 2). Significant difference was found between the mean estimates for the intervention group and the control group at 1-year follow-up (intervention group, mean estimate $=10.77, \mathrm{SE}=0.93,95 \% \mathrm{CI}$ : 8.91 to 12.60 ; control group, mean estimate $=13.83, \mathrm{SE}=0.96,95 \% \mathrm{CI}: 11.90$ to 15.65; estimated mean difference $=3.01,95 \% \mathrm{CI}: 0.39$ to $5.63, P=0.03$ ). The effect size (Hedges' $g$ ) for between-group differences at 1-year follow-up was -0.45 (95\% CI: -0.85 to -0.05). Additionally, a significant difference was found in estimated means between the intervention group and the control group at posttreatment (intervention group, mean estimate $=6.45, \mathrm{SE}=0.93,95 \% \mathrm{CI}$ : 4.62 to 8.29 ; control group, mean estimate $=12.77, \mathrm{SE}=0.96,95 \% \mathrm{CI}: 10.95$ to 14.69 ; estimated mean difference $=6.37,95 \% \mathrm{CI}: 3.75$ to $8.99, P<0.01)$. The effect size (Hedges' $g$ ) for between-group differences at 1-year follow-up was -0.90 (95\% CI: -1.33 to -0.51$)$. No discrepancy was found between the results of ITT and complete case analysis.

\section{Prophylactic effects for onset of MDD}

We assessed the significance of differences between the intervention group $(n=51)$ and the control group $(n=49)$ in developing MDD during the 1-year follow-up. In CIDI, participants who met the criteria for MDD responded that they had developed depressive symptoms. In addition, participants reported the time as 1) within 1 month, 2) between 2 and 6 months, and 3) between 7 and 12 months after baseline assessment.

Two participants in the intervention group developed MDD during 1-year follow-up (one participant within the previous 1 month, one participant in the previous 2-6 months: $2 / 51,3.92 \%)$. Four control group participants developed MDD (one participant 2-6 months before, three participants 7-12 months before: 4/49, 8.16\%). Three participants of the intervention group and eight participants in the control group had an MDD history longer than 1 year before the screening of this study. We applied Cox proportional hazard analysis to assess differences in survival probabilities between the intervention group and the control group. We used the MDD

Table 2 Results of linear mixed model

\begin{tabular}{|c|c|c|c|c|c|}
\hline \multicolumn{6}{|c|}{ Intention-to-treat analysis } \\
\hline \multirow[t]{2}{*}{ Score } & Time & $\begin{array}{l}\text { Intervention } \\
\text { group }(n=62)\end{array}$ & $\begin{array}{l}\text { Control } \\
\text { group }(n=56)\end{array}$ & $95 \% \mathrm{Cl}$ & $P$-value \\
\hline & & Estimate (SE) & Estimate (SE) & & \\
\hline \multirow[t]{3}{*}{ BDI-II } & Pretreatment & $12.76(0.83)$ & $13.30(0.88)$ & -2.93 to 1.89 & 0.65 \\
\hline & Posttreatment & $7.03(0.84)$ & $12.77(0.88)$ & 3.34 to 8.14 & 0.00 \\
\hline & I-year follow-up & $11.00(0.89)$ & $13.83(0.91)$ & 0.28 to 5.33 & 0.03 \\
\hline \multicolumn{6}{|c|}{ Complete case analysis } \\
\hline \multirow[t]{2}{*}{ Score } & Time & $\begin{array}{l}\text { Intervention } \\
\text { group }(n=51)\end{array}$ & $\begin{array}{l}\text { Control } \\
\text { group }(n=49)\end{array}$ & $95 \% \mathrm{Cl}$ & $P$-value \\
\hline & & Estimate (SE) & $\overline{\text { Estimate (SE) }}$ & & \\
\hline \multirow[t]{3}{*}{ BDI-II } & Pretreatment & $12.63(0.93)$ & $13.18(0.96)$ & -2.06 to 3.18 & 0.65 \\
\hline & Posttreatment & $6.45(0.93)$ & $12.77(0.96)$ & 3.75 to 8.99 & 0.00 \\
\hline & I-year follow-up & $10.77(0.93)$ & $13.83(0.96)$ & 0.39 to 5.63 & 0.03 \\
\hline
\end{tabular}

Note: Values in parentheses are SEs.

Abbreviations: BDI-II, Beck Depression Inventory, second edition; SE, standard error. 


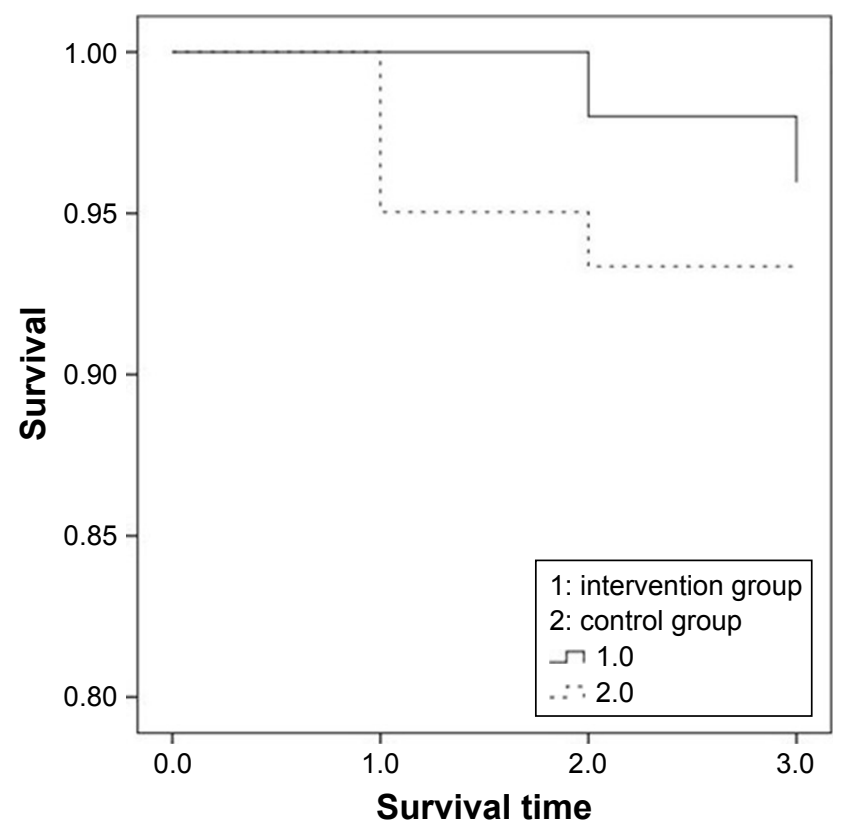

Figure 3 Survival curve.

Notes: Survival times are shown for three times. Time I is 7-12 months before the I-year follow-up period. Time 2 is $2-6$ months before the I-year follow-up period. Time 3 is within I month from the I-year follow-up period.

history as a covariate. No significant difference was found in these results $\left(\chi^{2}=2.51, P=0.11\right.$; Figure 3$)$.

\section{Discussion}

Results of linear mixed modeling for a repeated measures approach show that late adolescent students receiving treatment had significantly different BDI-II scores from those of the control group at 1-year follow-up. The effect size for between-group differences at 1-year follow-up was -0.41 . Next, we conducted a complete case analysis and performed sensitivity analysis necessary to examine the discrepancy between ITT and a complete case analysis. The effect size of complete case analysis for between-group differences in 1 -year follow-up was -0.45 . Results showed no discrepancy between ITT analysis and complete case analysis. Sensitivity analysis can be done using a different approach to assess the robustness of the primary analysis to the chosen method for handling missing data. ${ }^{34}$ Therefore, the primary analysis of this study is regarded as robust. An earlier study, a meta-analysis of psychological treatments for subthreshold depression, found no significant effect of psychotherapies for depressive symptoms between an intervention group and a control group at 1-year follow-up. ${ }^{13}$ An earlier study of college students found no significant effect for the CBT group on depressive symptoms compared to either bibliotherapy or brochure controls at either 3- or 6-month follow-up. ${ }^{38}$
Results of our earlier report indicated that late adolescents with subthreshold depression had a lower frequency of environmental rewards than healthy late adolescents. ${ }^{39}$ Our behavioral activation program emphasized increased access to positive reinforcement activities to improve the rate of response-contingent positive reinforcement. These results demonstrate that late adolescent students receiving treatment had significantly different BDI-II scores from those of the assessment-only control group at 1-year follow-up.

However, the effect size for between-group differences at 1 -year follow-up was -0.41 . The effect size of intervention can be regarded as small. Our earlier study revealed the effect size of behavioral activation program as -0.90 for betweengroup differences in acute treatment. ${ }^{19}$ Therefore, the behavioral activation program effect decreased during 1 year. Moreover, we attempted to ascertain whether a 5-week shortterm behavioral activation program can decrease the risk of developing MDD compared to a control group or not. Results of Cox proportional hazard analysis revealed no significant difference between the intervention group and the control group in the incidence of MDD. Although a significant difference was found in the depressive symptoms at 1-year follow-up between the intervention group and the control group, one must interpret the results carefully. In terms of the considerable reduction in effects between posttreatment and follow-up, although some earlier studies conducted booster sessions or continuation sessions to maintain the effects of intervention, ${ }^{40,41}$ we conducted no such booster sessions. The knowledge that continued support would be provided via booster sessions might have reinforced participants' confidence in managing depression or anxiety. ${ }^{42}$ An earlier report described from a meta-analysis that CBT intervention with a booster session is more effective in terms of sustainability than CBT interventions without booster sessions. ${ }^{42}$ To maintain behavioral activation effects, it is necessary to review activities in booster sessions. Moreover, it is very difficult to obtain large effects if baseline depressive symptoms are as low as they were in this study. Furthermore, the behavioral activation intervention was very brief. It can be regarded as a low-intensity intervention. Therefore, long-term effects of such treatment might be less likely to be apparent.

Some study limitations are related to the sample used for this study. The sample size calculations were conducted at the study design stage. However, this sample size was based on the study design of an earlier study. ${ }^{19}$ An earlier report described that 200 participants per condition must be tested for a difference in the incidence rate. ${ }^{40}$ Although we assessed differences in the incidence of MDD between the 
intervention group and the control group in a preliminary study, the sample size of this study was small. A future study using a large sample size must be undertaken to examine the incidence of MDD. Secondly, in this study, we confirmed whether the participants were undergoing psychopharmacological or psychological treatment in CIDI or not. Participants who were not undergoing psychopharmacological or psychological treatment were included in this study. We confirmed the current treatment in this study. Therefore, future studies must be conducted to target people who have never received psychopharmacological or psychological treatment. Despite the limitations described above, the results of this study show a significant difference in BDI-II scores between the intervention group and the control group at 1-year follow-up.

\section{Conclusion}

Although our behavioral activation program is simple and brief, the results obtained at 1-year follow-up indicate a significant difference between the BDI-II scores of the late adolescent control group students and the students receiving treatment. Our 5-week behavioral activation program based on behavioral characteristics for subthreshold depression appears to be promising for treating subthreshold depression.

\section{Acknowledgments}

This study was supported by Grants-in-Aid for Scientific Research on Innovative Areas, Grant Numbers 16H06395 and 16H06399 from Japan Society for the Promotion of Science, and Grant Number 23118004 from the Ministry of Education, Culture, Sports, Science and Technology, Japan. No funding entity influenced the results or presentation of the study results. The authors would like to thank all participants.

\section{Author contributions}

All authors contributed to the design, acquisition of data, interpretation of data drafting, and critical revision of the paper, and agree to be accountable for all aspects of the work. All authors have approved the final article.

\section{Disclosure}

The authors have no conflict of interest, financial or otherwise, related to this study.

\section{References}

1. Pincus HA, Davis WW, Mcqueen LE. 'Subthreshold' mental disorders. A review and synthesis of studies on minor depression and other brand names. Br J Psychiatry. 1999;174:288-296.
2. Bertha EA, Balázs J. Subthreshold depression in adolescence: a systematic review. Eur Child Adolesc Psychiatry. 2013;22(10):589-603.

3. Fergusson DM, Horwood LJ, Ridder EM, Beautrais AL. Suicidal behaviour in adolescence and subsequent mental health outcomes in young adulthood. Psychol Med. 2005;35(7):983-993.

4. Johnson JG, Cohen P, Kasen S. Minor depression during adolescence and mental health outcomes during adulthood. Br J Psychiatry. 2009; 195(3):264-265.

5. Jinnin R, Okamoto Y, Takagaki K, et al. Detailed course of depressive symptoms and risk for developing depression in late adolescents with subthreshold depression: a cohort study. Neuropsychiatr Dis Treat. 2017;13:25-33.

6. Rohde P, Beevers CG, Stice E, O'Neil K. Major and minor depression in female adolescents: onset, course, symptom presentation, and demographic associations. J Clin Psychol. 2009;65(12):1339-1349.

7. Balázs J, Miklósi M, Keresztény A, et al. Adolescent subthresholddepression and anxiety: psychopathology, functional impairment and increased suicide risk. J Child Psychol Psychiatry. 2013;54(6): 670-677.

8. González-Tejera G, Canino G, Ramírez R, et al. Examining minor and major depression in adolescents. J Child Psychol Psychiatry. 2005; 46(8):888-899.

9. Hammad TA, Laughren T, Racoosin J. Suicidality in pediatric patients treated with antidepressant drugs. Arch Gen Psychiatry. 2006; 63(3):332-339.

10. Clarke GN, Hawkins W, Murphy M, Sheeber LB, Lewinsohn PM, Seeley JR. Targeted prevention of unipolar depressive disorder in an at-risk sample of high school adolescents: a randomized trial of a group cognitive intervention. $J$ Am Acad Child Adolesc Psychiatry. 1995;34(3):312-321.

11. Clarke GN, Hornbrook M, Lynch F, et al. A randomized trial of a group cognitive intervention for preventing depression in adolescent offspring of depressed parents. Arch Gen Psychiatry. 2001;58(12): $1127-1134$.

12. Imamura K, Kawakami N, Furukawa TA, et al. Does Internet-based cognitive behavioral therapy (iCBT) prevent major depressive episode for workers? A 12-month follow-up of a randomized controlled trial. Psychol Med. 2015;45(9):1907-1917.

13. Cuijpers P, Smit F, van Straten A. Psychological treatments of subthreshold depression: a meta-analytic review. Acta Psychiatr Scand. 2007;115(6):434-441.

14. Mccauley E, Gudmundsen G, Schloredt K, et al. The Adolescent Behavioral Activation Program: adapting behavioral activation as a treatment for depression in adolescence. J Clin Child Adolesc Psychol. 2016;45(3):291-304.

15. Wallis A, Roeger L, Milan S, Walmsley C, Allison S. Behavioural activation for the treatment of rural adolescents with depression. Aust J Rural Health. 2012;20(2):95-96.

16. Gawrysiak M, Nicholas C, Hopko DR. Behavioral activation for moderately depressed university students: randomized controlled trial. J Couns Psychol. 2009;56(3):468-475.

17. Martin F, Oliver T. Behavioral activation for children and adolescents: a systematic review of progress and promise. Eur Child Adolesc Psychiatry. Epub 2018 Feb 23.

18. Ekers D, Webster L, van Straten A, Cuijpers P, Richards D, Gilbody S. Behavioural activation for depression; an update of metaanalysis of effectiveness and sub group analysis. PLoS One. 2014;9(6): e100100.

19. Takagaki K, Okamoto Y, Jinnin R, et al. Behavioral activation for late adolescents with subthreshold depression: a randomized controlled trial. Eur Child Adolesc Psychiatry. 2016;25(11):1171-1182.

20. Allart-van Dam E, Hosman CMH, Hoogduin CAL, Schaap CPDR. The coping with depression course: short-term outcomes and mediating effects of a randomized controlled trial in the treatment of subclinical depression. Behav Ther. 2003;34(3):381-396. 
21. Furukawa TA, Horikoshi M, Kawakami N, et al. Telephone cognitivebehavioral therapy for subthreshold depression and presenteeism in workplace: a randomized controlled trial. PLoS One. 2012; 7(4):e35330

22. Imamura K, Kawakami N, Furukawa TA, et al. Effects of an Internetbased cognitive behavioral therapy (iCBT) program in Manga format on improving subthreshold depressive symptoms among healthy workers: a randomized controlled trial. PLoS One. 2014;9(5):e97167.

23. Spek V, Nyklícek I, Smits N, et al. Internet-based cognitive behavioural therapy for subthreshold depression in people over 50 years old: a randomized controlled clinical trial. Psychol Med. 2007;37(12): 1797-1806.

24. Vázquez FL, Torres A, Blanco V, Díaz O, Otero P, Hermida E. Comparison of relaxation training with a cognitive-behavioural intervention for indicated prevention of depression in university students: a randomized controlled trial. J Psychiatr Res. 2012;46(11):1456-1463.

25. Simon GE, Ludman EJ, Tutty S, Operskalski B, von Korff M. Telephone psychotherapy and telephone care management for primary care patients starting antidepressant treatment: a randomized controlled trial. JAMA. 2004;292(8):935-942.

26. Wang PS, Simon GE, Avorn J, et al. Telephone screening, outreach, and care management for depressed workers and impact on clinical and work productivity outcomes: a randomized controlled trial. JAMA. 2007;298(12):1401-1411.

27. Beck AT, Steer RA, Brown GK. Beck Depression Inventory: Manual. 2nd ed. Antonio S, editor. Texas: The Psychological Corp; 1996.

28. Kojima M, Furukawa T. Japanese Version of the Beck Depression Inventory. 2nd ed. Tokyo: Nippon-Hyoron-sha Co; 2003.

29. Kessler RC, Üstün TB. The World Mental Health (WMH) Survey Initiative version of the World Health Organization (WHO) Composite International Diagnostic Interview (CIDI). Int J Methods Psychiatr Res. 2004;13(2):93-121.

30. Kawakami N, Takeshima T, Ono Y, et al. Twelve-month prevalence, severity, and treatment of common mental disorders in communities in Japan: preliminary finding from the World Mental Health Japan Survey 2002-2003. Psychiatry Clin Neurosci. 2005;59(4):441-452.
31. Hirschfeld RM. The comorbidity of major depression and anxiety disorders: recognition and management in primary care. Prim Care Companion J Clin Psychiatry. 2001;3(6):244-254.

32. Cuijpers P, van Straten A, Warmerdam L. Behavioral activation treatments of depression: a meta-analysis. Clin Psychol Rev. 2007; 27(3):318-326.

33. Cohen J. Statistical Power Analysis for the Behavioral Sciences. 2nd ed. Hillsdale, NJ: Erlbaum Associates; 1998.

34. Thabane L, Mbuagbaw L, Zhang S, et al. A tutorial on sensitivity analyses in clinical trials: the what, why, when and how. BMC Med Res Methodol. 2013;13:92.

35. Peters SA, Bots ML, den Ruijter HM, et al. Multiple imputation of missing repeated outcome measurements did not add to linear mixedeffects models. J Clin Epidemiol. 2012;65(6):686-695.

36. Son H, Friedmann E, Thomas SA. Application of pattern mixture models to address missing data in longitudinal data analysis using SPSS. Nurs Res. 2012;61(3):195-203.

37. Hedges LV. Distribution theory for Glass's estimator of effect size and related estimators. J Educ Stat. 1981;6(2):107-128.

38. Rohde P, Stice E, Shaw H, Gau JM. Cognitive-behavioral group depression prevention compared to bibliotherapy and brochure control: nonsignificant effects in pilot effectiveness trial with college students. Behav Res Ther. 2014;55:48-53.

39. Takagaki K, Okamoto Y, Jinnin R, et al. Behavioral characteristics of subthreshold depression. J Affect Disord. 2014;168:472-475.

40. Allart-van Dam E, Hosman CM, Hoogduin CA, Schaap CP. Prevention of depression in subclinically depressed adults: follow-up effects on the 'Coping with Depression' course. J Affect Disord. 2007; 97(1-3):219-228.

41. Garber J, Clarke GN, Weersing VR, et al. Prevention of depression in at-risk adolescents: a randomized controlled trial. JAMA. 2009; 301(21):2215-2224.

42. Gearing RE, Schwalbe CS, Lee R, Hoagwood KE. The effectiveness of booster sessions in CBT treatment for child and adolescent mood and anxiety disorders. Depress Anxiety. 2013;30(9):800-808.
Neuropsychiatric Disease and Treatment

\section{Publish your work in this journal}

Neuropsychiatric Disease and Treatment is an international, peerreviewed journal of clinical therapeutics and pharmacology focusing on concise rapid reporting of clinical or pre-clinical studies on a range of neuropsychiatric and neurological disorders. This journal is indexed on PubMed Central, the 'PsycINFO' database and CAS,

\section{Dovepress}

and is the official journal of The International Neuropsychiatric Association (INA). The manuscript management system is completely online and includes a very quick and fair peer-review system, which is all easy to use. Visit http://www.dovepress.com/testimonials.php to read real quotes from published authors. 